\title{
PENGARUH PENDIDIKAN KESEHATAN DENGAN MEDIA POSTER TERHADAP PENGETAHUAN MANAJEMEN HIPERTENSI PADA PENDERITA HIPERTENSI
}

\author{
Zakiyatul Ulya', Asep Iskandar², Fajar Tri Asih ${ }^{3}$ \\ ${ }^{1}$ Nursing Student, Nursing Program, Faculty of Health Science, University of Jenderal \\ Soedirman \\ ${ }^{2}$ Nursing Program, Faculty of Health Science, University of Jenderal Soedirman \\ 3Public Health Office Banyumas \\ Email: zulya7911@gmail.com
}

\begin{abstract}
ABSTRAK
Pengetahuan manajemen hipertensi yang rendah dapat menyebabkan tidak terkontrolnya tekanan darah dan timbulnya komplikasi penyakit lain. Pengetahuan hipertensi dapat ditingkatkan dengan pendidikan kesehatan. Media dibutuhkan saat pendidikan kesehatan untuk memudahkan penyampaian informasi. Poster merupakan salah satu media pendidikan kesehatan yang menggunakan huruf disertai gambar dan dapat ditempel dimanapun sehingga dapat dijadikan pengingat informasi yang diberikan. Penelitian ini merupakan quasi experiment dengan desain pre-test and post-test non equivalent control group. Pengambilan sampel menggunakan metode consecutive sampling. Sampel berjumlah 32 orang dan dibagi dalam 2 kelompok, yaitu kelompok intervensi dan kontrol. Analisis data menggunakan Paired t-test dan Independent t-test. Sebagian besar responden berusia 45-60 tahun, berjenis kelamin perempuan, berpendidikan Sekolah Dasar (SD), dan sebagian besar bekerja sebagai ibu rumah tangga. Hasil uji Paired t-test terdapat perbedaan peningkatan pengetahuan yang signifikan pada kelompok intervensi ( $p$ $=0,000)$ dibandingkan kelompok kontrol $(p=0,194)$. Hasil uji Independent $t$-test menunjukkan ada peningkatan pengetahuan antara kelompok intervensi dan kontrol $(p=$ 0,016). Pendidikan kesehatan dengan media poster efektif meningkatkan pengetahuan manajemen hipertensi pada penderita hipertensi.
\end{abstract}

Kata Kunci: Hipertensi, Pengetahuan, Manajemen Hipertensi, Poster

\section{ABSTRACT}

The low hypertension management knowledg causes uncontrolled high blood pressure and it's complication. A health education may increase the hypertension management knowledge. Poster is one of the health education media consisting letters, picture, and can be patch anywhere, so it can be read repeatedly. This was a quasy experiment with pre and post-test non equivalent control group design. This study recruited the respondents using a consecutive sampling method. The sample size was 32 respondents which divided into intervention and control group. The data were analyzed using Paired t-test and Independent t-test. The majority of respondents were age between 45-60 years old, female, housewife, and graduated elementary school. The Paired t-test results showed that there were significant differences of the knowledge pre and post-test scores in the intervention group $(p=0,000)$ and control group $(p=0,194)$. The Independent t-test results showed that there were significant differences between the knowledge post-test scores among the intervention group and control group $(p=0,016)$. Health education using posters may improve the hypertension management knowledge among the hypertension patients. 
Keywords: Hypertension, Hypertension Management Knowledge, Poster

\section{PENDAHULUAN}

Hipertensi merupakan masalah kesehatan utama di dunia. Menurut data World Health Organization (WHO) pada tahun 2011, 26,4\% penduduk di dunia menderita hipertensi dan kemungkinan akan meningkat menjadi $29,2 \%$ pada tahun 2025. Hasil Riset Kesehatan Dasar tahun 2013 menunjukkan bahwa 26,5\% penduduk Indonesia terkena hipertensi dan Jawa Tengah menempati peringkat ke-delapan terjadinya hipertensi di Indonesia yaitu sebesar 26,4\% (Kementrian Kesehatan Republik Indonesia [Kemenkes R.I.], 2013). Data yang diperoleh dari Dinas Kesehatan Banyumas jumlah penderita hipertensi pada bulan Januari-September 2016 sebanyak 8690 kasus, lebih tinggi dibandingkan tahun sebelumnya yang mencapai 7223 kasus.

Hipertensi yang berlangsung dalam jangka waktu lama dan tidak terkontrol akan menimbulkan komplikasi pada organ lain. Smeltzer dan Bare (2008) mengatakan komplikasi yang dapat terjadi pada hipertensi adalah stroke, infark miokard, dan gagal ginjal. Soenarta, Erwinanto, Mumpuni, Barack, Lukito, Hersunarti, dan Pratikto (2015) mengatakan bahwa hipertensi merupakan penyakit yang tidak dapat disembuhkan, namun dapat dikendalikan agar tekanan darah tetap stabil sehingga mengurangi risiko komplikasi pada organ lain. Selain itu, menurut Kang (2016) manajemen hipertensi adalah salah satu hal yang dapat dilakukan sebagai upaya mencegah terjadinya komplikasi pada penyakit lain. Menurut Kemenkes R.I. (2014) manajemen hipertensi yang dilakukan antara lain kombinasi obatobatan dan modifikasi gaya hidup, seperti membatasi asupan garam, olahraga, istirahat, mengendalikan stres serta menghindari makanan-makanan tertentu yang dapat memperparah tekanan darah seseorang.

Pengetahuan masyarakat mengenai manajemen hipertensi saat ini masih kurang. Pendidikan merupakan salah satu cara yang dapat digunakan untuk meningkatkan pengetahuan seseorang. Pendidikan dapat diberikan pada berbagai bidang, termasuk kesehatan. Notoatmodjo (2012) menyebutkan bahwa pendidikan kesehatan adalah suatu proses yang dapat meningkatkan derajat kesehatan seseorang. Pendidikan kesehatan dapat diberikan kepada seluruh sasaran, namun harus menggunakan metode yang tepat agar informasi yang diberikan dapat diterima dengan baik.

Terdapat berbagai macam media pendidikan kesehatan yang dapat digunakan, namun tidak semuanya dapat diterapkan pada seluruh usia. Pada pra lansia yang sering dikaitkan dengan kemunduran fungsi fisik maupun kognitif membutuhkan suatu media untuk memudahkan pemahaman informasi yang diberikan dan dijadikan sebagai pengingat meskipun tidak dalam proses pemberian pendidikan kesehatan. Poster merupakan salah satu media pendidikan kesehatan yang menggunakan huruf dengan ukuran besar dan jelas serta disertai gambar (Wongsawat, 2015). Hal tersebut dapat minat pembaca dan memudahkan pemahaman informasi yang terdapat didalamnya. Selain itu, poster juga dapat ditempel di rumah maupun tempat umum sehingga dapat dijadikan pengingat (Maharani, 2011).

Hasil studi pendahuluan yang dilakukan pada 10 penderita hipertensi di Desa Banteran menunjukkan 8 dari 10 
penderita hipertensi tidak mengetahui apa yang dianjurkan dan tidak dianjurkan bagi penderita hipertensi, mereka hanya mengetahui dilarang mengkonsumsi makanan yang banyak mengandung garam. Semua penderita hipertensi yang diwawancari mengatakan bahwa tidak pernah dilakukan pendidikan kesehatan selain saat posyandu lansia. Pendidikan kesehatan yang diberikan biasanya hanya sekedar ceramah saat diukur tekanan darahnya termasuk tinggi.

$$
\text { Kurangnya pendidikan }
$$

kesehatan mengenai manajemen hipertensi menyebabkan kurangnya pengetahuan pada penderita hipertensi. Masyarakat membutuhkan pendidikan kesehatan mengenai manajemen hipertensi disertai dengan media yang sesuai agar dapat meningkatkan pengetahuan manajemen hipertensi. Berdasarkan hal tersebut, peneliti tertarik untuk melakukan penelitian yang berjudul "Pengaruh Pendidikan Kesehatan dengan Media Poster terhadap Pengetahuan Manajemen Hipertensi pada Penderita Hipertensi di Desa Banteran, Kebupaten Banyumas."

\section{METODE}

Penelitian ini merupakan penelitian kuantitatif quasi experiment dengan desain pre-test and post-test non equivalent control group. Terdapat dua kelompok, yaitu kontrol dan intervensi. Kedua kelompok pre-test sebelum intervensi. Kedua kelompok diberikan pendidikan kesehatan dengan ceramah secara bersamaan, kemudian untuk kelompok intervensi dibagikan poster yang diberikan secara langsung dari peneliti ke rumah responden. Kedua kelompok melakukan post-test setelah satu minggu.

Analisis yang dilakukan yaitu analisis univariat dan bivariat. Analisis data univariat pada penelitian bertujuan untuk mendeskripsikan semua variabel yang diteliti. Sedangkan analisis bivariat pada penelitian ini dilakukan untuk

Tabel 4.1 Karakteristik Usia Responden

\begin{tabular}{lccll}
\hline Karakteristik Usia & Mean & Min. & Max. & SD \\
\hline $\begin{array}{l}\text { Kelompok } \\
\text { Intervensi }\end{array} 53,88$ & 48 & 60 & 4,225 \\
Kelompok Kontrol & 54,31 & 45 & 60 & 4,527 \\
\hline
\end{tabular}

membuktikan hipotesis dari penelitian.

HASIL

Penelitian ini telah dilaksanakan pada tanggal 29 November sampai 19 Desember 2016. Analisa data menggunakan Dependen T-Test dan Independent T-Test. Karakteristik responden yang dilihat pada penelitian ini meliputi usia, jenis kelamin, pendidikan, dan pekerjaan. Jenis kelamin responden pada penelitian ini $100 \%$ adalah perempuan. Pendidikan terakhir responden pada penelitian ini 100\% Sekolah Dasar (SD).

Tabel 4.2 Distribusi Frekuensi Karakteristik Pekerjaan

\begin{tabular}{lrrrr}
\hline \multirow{2}{*}{ Karakteristik } & \multicolumn{2}{c}{$\begin{array}{c}\text { Kelompok } \\
\text { intervensi }\end{array}$} & \multicolumn{2}{c}{$\begin{array}{c}\text { Kelompok } \\
\text { kontrol }\end{array}$} \\
\cline { 2 - 5 } & $\mathrm{n}$ & $\%$ & $\mathrm{n}$ & $\%$ \\
\hline Pekerjaan & & & & \\
Swasta & 5 & 31,2 & 2 & 12,5 \\
Buruh & 3 & 18,8 & 3 & 18,8 \\
IRT & 6 & 37,5 & 7 & 43,8 \\
Petani & 2 & 12,5 & 4 & 25,0 \\
\hline
\end{tabular}

Tabel 4.1 menunjukkan bahwa usia minimal pada penelitian ini 45 tahun dan usia maksimalnya 60 tahun. Tabel 4.2 menunjukkan distribusi frekuensi karakteristik responden berdasarkan pekerjaan pada kelompok intervensi dan kelompok kontrol. Hasil tersebut menunjukkan bahwa hampir $>50 \%$ responden merupakan ibu rumah tangga 
Tabel 4.3 Perbedaan Peningkatan Skor Pengetahuan Manajemen Hipertensi Responden Sebelum dan Sesudah Perlakuan pada Kelompok Intervensi dan Kelompok Kontrol

\begin{tabular}{ccccccccc}
\hline \multirow{2}{*}{ Kelompok } & \multicolumn{3}{c}{ Sebelum } & \multicolumn{3}{c}{ Sesudah } & \multirow{2}{*}{$\mathrm{N}$} \\
\cline { 2 - 7 } & Mean & SD & SE & Mean & SD & SE & & \\
\hline Intervensi & 65,06 & 6,547 & 1,637 & 71,25 & 7,594 & 1,898 & 0,000 & 16 \\
Kontrol & 64,06 & 6,060 & 1,515 & 65,06 & 5,961 & 1,490 & 0,194 & 16 \\
\hline
\end{tabular}

Tabel 4.4 Perbedaan Peningkatan Rerata Skor Pengetahuan Manajemen Hipertensi Responden pada Kelompok Intervensi dan Kelompok Kontrol

\begin{tabular}{lcccc}
\hline Kelompok & Mean & SE & $p$ & $N$ \\
\hline Intervensi & 5,250 & 1,047 & 0,001 & 16 \\
Kontrol & & & & 16 \\
\hline
\end{tabular}

yaitu 6 responden $(37,5 \%)$ pada kelompok intervensi dan 7 responden $(43,8)$ pada kelompok kontrol.

Tabel 4.3 menunjukkan uji Paired T-Test mendapatkan hasil bahwa kelompok intervensi memiliki nilai $p$ $<0,05$ yaitu 0,000 . Sedangkan pada kelompok kontrol didapatkan nilai $p=$ 0,194 atau $>0,05$ yang menunjukkan bahwa tidak ada perbedaan yang bermakna pada skor pengetahuan manajemen hipertensi kelompok kontrol. Tabel 4.4 menunjukkan bahwa hasil uji statistik diperoleh $p$ value sebesar 0,001 . Hasil tersebut menunjukkan bahwa $p$ value $<0,05$, maka Ha diterima.

\section{PEMBAHASAN}

Hasil penelitian ini menunjukkan distribusi frekuensi usia berada pada rentang 45 sampai 60 tahun. Usia responden terbanyak 60 tahun, hal tersebut menunjukkan bahwa semakin bertambahnya usia maka semakin berisiko terjadinya hipertensi. Semakin bertambah usia, maka terjadi perubahan struktural dan fungsional pada sistem pembuluh darah sehingga dapat menimbulkan kenaikan tekanan darah. Menurut Smeltzer dan Bare (2008) perubahan yang terjadi antara lain aterosklerosis, hilangnya elastisitas jaringan ikat, dan penurunan relaksasi otot polos pembuluh darah. Perubahan tersebut akan mempengaruhi kemampuan aorta dan arteri besar mengakomodasi volume darah yang dipompa jantung sehingga akan terjadi penurunan curah jantung dan peningkatan tahanan perifer (Smeltzer \& Bare, 2008).

Peneliti hanya memilih responden yang berusia 45-60 tahun. Pembatasan usia dilakukan untuk memudahkan penerimaan materi pendidikan kesehatan yang diberikan oleh peneliti. Semakin tua usia maka semakin sulit kemampuan penerimaan dan pemahaman materinya. Erfandi (2009) mengatakan bahwa usia dapat berpengaruh terhadap daya tangkap dan pola pikir seseorang.

Distribusi pendidikan responden pada kedua kelompok 100\% berpendidikan terakhir Sekolah Dasar (SD) atau sederajat. Tingkat pendidikan yang setara pada kedua kelompok dapat memudahkan penelitian karena informasi yang telah dimiliki relatif sama. Terbukti saat penelitian kedua kelompok berada pada rentang tingkat pengetahuan yang sama saat sebelum diberikan pendidikan 
kesehatan. Sriyono (2015) mengatakan bahwa tinggi rendahnya tingkat pendidikan seseorang menentukan pengetahuan, sikap dan perilakunya. Tingkat pendidikan tidak hanya mempengaruhi tingkat pengetahuan seseorang, namun juga kemampuan penerimaan informasi. Setaranya tingkat pendidikan responden pada penelitian ini diharapkan agar kemampuan pemahaman informasi sama antar responden. Hal tersebut dibuktikan dengan hasil posttest responden yang berada pada rentang tingkat pengetahuan yang sama dan dapat menunjukkan bahwa kemampuan pemahaman pendidikan kesehatan yang diberikan sama antar responden sesuai dengan intervensi yang diterimanya.

Distribusi jenis kelamin pada kedua kelompok adalah sama yaitu $100 \%$ perempuan. Hal tersebut terjadi karena posyandu lansia di Desa Banteran, Kecamatan Sumbang, Banyumas selalu diadakan pada pagi hari sehingga warga yang mengikuti posyandu lansia tersebut mayoritas adalah perempuan. Hipertensi juga dapat dipengaruhi oleh jenis kelamin. Penelitian Chen, Lo, Chang, dan Kuo (2014) mendapatkan hasil $51.2 \%$ perempuan dan $48.8 \%$ laki-laki menderita hipertensi. Menurut Cheng, dkk (2014) perempuan lebih banyak menderita hipertensi setelah menopause, hal tersebut terjadi karena adanya penurunan hormon yang menyebabkan penurunan homeostatis tubuh. setelah usia 45 tahun perempuan lebih berisiko terkena hipertensi karena produksi hormon estrogen yang mempengaruhi kadar High Density Lipoprotein (HDL). Perubahan hormon tersebut dapat menyebabkan hipertensi dan penebalan pembuluh darah atau aterosklerosis.
Tingkat pengetahuan antara lakilaki dan perempuan berbeda satu sama lain. Penelitian Erkoc, Isikli, Metintas dan Kalyoncu (2012) menunjukkan bahwa perempuan mempunyai tingkat pengetahuan mengenai manajemen hipertensi yang lebih tinggi dibandingkan dengan laki-laki. Hal tersebut terjadi karena perempuan mempunyai keinginan yang kuat untuk mencari informasi mengenai kondisi yang ada di sekitarnya (Cant dan Scheers, 2012).

Jenis pekerjaan responden pada penelitian ini terdiri dari swasta, buruh, ibu rumah tangga, dan petani. Hasil distribusi frekuensi menunjukkan jenis pekerjaan terbanyak sebagai ibu rumah tangga. Hal ini sesuai dengan penelitian Rahmi (2015) yang menunjukkan bahwa sebagian besar responden penderita hipertensi bekerja sebagai ibu rumah tangga. Banyaknya penderita hipertensi yang bekerja sebagai ibu rumah tangga dapat disebabkan oleh kurangnya aktifitas fisik yang dilakukan. Hal ini dikarenakan orang yang tidak aktif cenderung mempunyai frekuensi denyut jantung yang lebih tinggi sehingga otot jantungnya harus bekerja lebih keras pada setiap kontraksi (Smeltzer dan Bare, 2008). Semakin keras dan sering otot jantung harus memompa maka semakin besar tekanan yang dibebankan pada arteri sehingga dapat menyebabkan peningkatan tekanan darah.

Pekerjaan yang sering berinteraksi dengan orang lain umumnya dapat memberikan informasi lebih banyak dibandingkan dengan pekerjaan yang lebih sedikit berinteraksi dengan orang lain. Hal tersebut dapat dijadikan sebagai sumber informasi dalam hal tertentu. Informasi yang diperoleh dapat memberikan landasan kognitif 
terbentuknya pengetahuan terhadap hal tersebut (Notoatmojo, 2012).

Uji Paired T-Test menunjukkan adanya perbedaan skor pengetahuan manajemen hipertensi sebelum dan sesudah perlakuan pada kelompok intervensi memperoleh hasil nilai $p=0,000(p<0,05)$ yang berarti ada perbedaan yang bermakna pada skor pengetahuan manajemen hipertensi sebelum dan sesudah perlakuan.

Hasil tersebut menunjukkan bahwa pendidikan kesehatan dapat meningkatkan pengetahuan seseorang. Keberhasilan pendidikan kesehatan juga dapat didukung dengan adanya alat bantu atau media untuk membantu memudahkan penyampaian pesan atau materi yang ingin disampaikan. Salah satu media pendidikan kesehatan yang digunakan oleh peneliti adalah media poster. Poster merupakan media visual yang digunakan untuk menyampaikan pesan atau materi melalui gambar, warna, dan tulisan (Daryanto, 2015). Hal tersebut dapat meningkatkan minat pembaca untuk membaca informasi yang ada didalamnya. Beberapa responden saat penelitian mengatakan tertarik untuk membaca poster karena disertai warna dan gambar sehingga penasaran dan dibaca berulang kali. Selain itu, bentuknya yang sederhana dan mudah ditempel dimana saja memudahkan pembaca untuk membaca poster tersebut tanpa harus mencarinya terlebih dahulu.

Uji Paired T-Test perbedaan skor pengetahuan manajemen hipertensi sebelum dan sesudah perlakuan pada kelompok kontrol memperoleh hasil nilai $p=0,194(p>0,05)$ yang berarti tidak ada perbedaan yang bermakna pada kelompok kontrol. Menurut Notoatmodjo (2012) seseorang yang lebih sering terpapar oleh informasi maka tingkat pengetahuannya lebih baik dibandingkan yang tidak terpapar informasi. Oleh karena itu, meskipun kedua kelompok diberikan pendidikan kesehatan dengan isi materi yang sama namun ketika kelompok intervensi diberikan poster maka pengetahuannya akan lebih baik dibandingkan dengan kelompok kontrol yang tidak diberikan poster.

Hasil penelitian menunjukkan skor pengetahuan manajemen hipertensi baik pada kelompok intervensi maupun kelompok kontrol sama-sama mengalami peningkatan setelah diberikan perlakuan. Namun, ada perbedaan yang bermakna pada peningkatan skor pengetahuan manajemen hipertensi antara kelompok intervensi dan kelompok kontrol. Hal ini dibuktikan dengan hasil uji Independent $T$-Test yang menghasilkan nilai $p=0,001$ $(p<0,05)$. Hal ini menunjukkan bahwa pendidikan kesehatan dengan media poster lebih efektif meningkatkan pengetahuan manajemen hipertensi dibandingkan dengan pemberian pendidikan kesehatan tanpa poster.

Media poster merupakan media yang menyajikan informasi dalam bentuk visual dan menstimulasi indera penglihatan. Menurut Notoatmodjo (2012) sebagian besar pengetahuan manusia diperoleh melalui indera penglihatan dan informasi lebih sering diingat apabila mereka dapat membaca informasi tersebut secara mandiri. Penggunaan media poster bertujuan untuk menyajikan informasi dalam bentuk yang menarik, mudah dimengerti, dan dapat dijadikan pengingat (Daryanto, 2015). Poster dapat ditempel di tempat strategis sehingga memudahkan seseorang untuk membaca informasi yang terdapat didalamnya. Apabila seseorang membaca poster berkali-kali maka informasi yang disampaikan di 
poster tersebut dapat dipahami dan diharapkan selain mempengaruhi pengetahuan juga memotivasi seseorang untuk mengikuti informasi yang terdapat didalamnya.

Penelitian ini didukung oleh penelitian Wongsawat (2015) yang telah membuktikan bahwa poster memiliki pengaruh yang bermakna terhadap pengetahuan diet diabetes tipe 2 pada penderita diabetes melitus tipe 2 dengan nilai $p=0,001(p<0,05)$. Hal tersebut diperkuat oleh penelitian Mamangkey (2015) yang menunjukkan bahwa penggunaan media poster memiliki pengaruh yang bermakna terhadap pengetahuan keluarga mengenai manajemen hipertensi. Meskipun demikian, belum ada referensi yang jelas mengenai frekuensi membaca poster yang dapat meningkatkan pengetahuan, sehingga saat penelitian frekuensi membaca poster antara responden satu dan yang lainnya berbeda-beda sehingga hal tersebut dapat mempengaruhi proses penyerapan dan pemahaman informasi yang terdapat didalamnya.

\section{SIMPULAN}

Karakteristik responden di Desa
Banteran, Kecamatan Sumbang, Banyumas berdasarkan usia adalah usia 45-60 tahun, keseluruhan jenis kelamin perempuan, pendidikan terakhir SD, dan sebagian besar responden bekerja sebagai ibu rumah tangga. Hasil uji Paired T-Test terdapat perbedaan rerata skor pengetahuan manajemen hipertensi yang bermakna sebelum dan sesudah perlakuan pada kelompok intervensi dan kelompok kontrol. Uji Independent T-Test menunjukkan terdapat perbedaan peningkatan rerata skor pengetahuan manajemen hipertensi yang bermakna antara kelompok intervensi dan kelompok kontrol. Hal tersebut menunjukkan bahwa pendidikan kesehatan menggunakan media poster lebih efektif meningkatkan pengetahuan manajemen hipertensi dibandingkan dengan tidak menggunakan poster.

\section{DAFTAR PUSTAKA}

Adib, M., 2009, Cara Mudah Memahami dan Menghindari Hipertensi Jantung dan Stroke, Dianloka, Yogyakarta.

Anggara Dwi, F H., dan Prayitno, N., 2013, Faktor-faktor yang Berhubungan denganTekanan Darah di Puskesmas Telaga Murni Cikarang Barat, Jurnal IImiah Kesehatan, 5 (1).

Anggraini, D., Zulpahiyana, Mulyanti, 2015, Faktor Dominan Lansia Aktif Mengikuti Kegiatan Posyandu di Dusun Ngentak, Jurnal Ners dan Kebidanan Indonesia, 150-155.

Anisa, D. N., 2012, Pengaruh Pendidikan Kesehatan terhadap Perilaku Cuci Tangan Pakai Sabun pada Anak Usia Sekolah di SD 2 Jambidan Banguntapan Bantul, Skripsi, STIKES 'AISYIYAH Yogyakarta, Yogyakarta.

Ardliyah, S. N., 2015, Pengaruh Edukasi Dengan Modul Pembelajaran terhadap Kepatuhan Diet Penderita Hipertensi di Desa Rempoah Kecamatan Baturaden Kabupaten Banyumas, Skripsi, Universitas Jenderal Soedirman, Purwokerto.

Arikunto S, 2006, Prosedur Penelitian Suatu Pendekatan Praktik, PT Rineka Cipta, Jakarta.

Asosiasi Dietsien Indonesia, 2006, Penuntun Diet, Gramedia Pustaka Utama, Jakarta. 
Baradero, M., Dayrit, W., dan Siswadi, Y., 2008. Klien Gangguan Kardiovaskular, EGC, Jakarta.

Cant, M., dan Scheers, L.V., 2012, Identifying the Correlation between the Gender and Knowledge of the South African Consumer in the Selection of Grocery Products, 2nd International Conference on Economics, Trade and Development, 36.

Chandra, B., 2009, Metodologi Penelitian Kesehatan, EGC, Jakarta.

Chen, K., Chiou, C.F., Plauschinat, C.A., Frech, F., Harer, A. \& Dubois, R., 2005, Patient Satisfaction with Antihypertensive Therapy, Journal of Human Hypertension, 19, 793799.

Dalyoko, D. A. P., 2010, Faktor-faktor yang Berhubungan dengan Upaya Pengendalian Hipertensi pada Lansia, Skripsi, Program Studi Kesehatan Masyarakat Universitas Muhammadiyah Surakarta, Surakarta.

Daryanto, 2015, Media Pembelajaran, Satu Nusa, Bandung.

Dawes, M., Kaczorowski, J., Swanson, G., Hickey, J., \& Karwalaitys, T., 2010, The Effect of a Patient Education Booklet and BP 'Tracker' on Knowledge About Hypertension, Oxford Journals, 472-478.

Dharma, K. K., 2011, Metodologi Penelitian Keperawatan, Trans Info Media, Jakarta.

Erkoc, S.B., Isikli, B., Metintas, S., dan Kalyoncu, C., 2012, Hypertension Knowledge-Level Scale (HK-LS): A Study on Development, Validity and Reliability, Int. J. Environ. Res. Public Health, 9, 1018-1029.
Giles, T., Materson, B., Cohn, J., Kostis, J., 2009, Definition and Classification of Hypertension: an Update, The Journal of Clinical Hypertensions, 11 (11).

Herlinah, L., Wiarsih, W., dan Rekawati, E., 2013, Hubungan Dukungan Keluarga dengan Perilaku Lansia dalam Pengendalian Hipertensi, Jurnal Keperawatan Komunitas, 1 (2) : 108-115.

Kang, H., 2016, A Mobile App for Hypertension Management Based on Clinical Practice Guidelines: Development and Deployment, JMIR Mhealth And Uhealth, 4 (1).

Kartikawati, A., 2008, Prevalensi dan Determinan Hipertensi pada Pasien Puskesmas di Jakarta Utara, Skripsi, Fakultas Kesehatan Masyarakat, Universitas Indonesia.

Kemenkes R.I., 2013, Riset Kesehatan Dasar, Kementerian Kesehatan Republik Indonesia, Jakarta.

Kemenkes R.I., 2014, Infodatin Hipertensi, Kementerian Kesehatan Republik Indonesia, Jakarta.

Kemenkes R.I., 2015, Rencana Strategis Kementerian Kesehatan, Kementerian Kesehatan Republik Indonesia, Jakarta.

Maharani, R., 2011, Pengaruh Pendidikan Kesehatan tentang Sadari terhadap Pengetahuan dan Sikap Remaja Putri dalam Upaya Deteksi Dini Kanker Payudara di SMK Bisnis Manajemen Administrasi Perkantoran Bina Satria Medan Tahun 2010, Skripsi, Universitas Sumatera Utara, Sumatera.

Mamangkey, J., 2015, Pengaruh Pendidikan Kesehatan Terhadap Pengetahuan Keluarga tentang 
Manajemen Hipertensi pada Lansia di desa Tupabbiring kecamatan Bontoa kabupaten Maros Sulawesi Selatan, Skripsi, Fakultas Kedokteran Universitas Hasanuddin, Makassar.

Notoatmodjo, S., 2012, Promosi Kesehatan dan IImu Perilaku, Rineka Cipta, Jakarta.

Nursalam, dan Efendi, F., 2008, Pendidikan dalam Keperawatan, Salemba Medika, Jakarta.

Oliveria, S.A., Chen, R.S., McCarthy, B.D., Hill, M.N., 2005, Hypertension knowledge, awareness, and attitudes in a hypertensive population, J Gen Intern Med, 20(3):219-25.

Rahmi, D. N., 2015, Efektifitas Terapi Humor Audio Digital dan Terapi Tertawa Terhadap Penurunan Tekanan Darah pada Penderita Hipertensi Primer di Desa Rempoah Kecamatan Baturaden Kabupaten Banyumas, Skripsi, Universitas Jenderal Soedirman, Purwokerto.

Simamora, R. H, 2009, Buku Ajar Pendidikan dalam Keperawatan, EGC, Jakarta.

Smeltzer, S. C., dan Bare, B. G., 2008, Buku Ajar Keperawatan MedikalBedah Brunner \& Suddarth, EGC, Jakarta.

Soenarta, A.A., Erwinanto, Mumpuni, A.S., Barack, R., Lukito, A.A., Hersunarti, N., Pratikto, R.S., 2015, Pedoman Tatalaksana
Hipertensi pada Penyakit Kardiovaskular, Perhimpunan Dokter Spesialis Kardiovaskular Indonesia, Jakarta.

Sriyono, 2015, Pengaruh Tingkat Pendidikan dan Pemahaman Masyarakat tentang Ikan Berformalin Terhadap Kesehatan Masyarakat, Faktor Exacta, 8 (1): 79-91.

Sumantri, A., 2014, Pengaruh Pendidikan Hipertensi pada Keluarga terhadap Kepatuhan Diet Rendah Garam Lansia Hipertensi di Kecamatan Sukolilo Kabupaten Pati, Skripsi, STIKES 'AISYIYAH Yogyakarta, Yogyakarta.

Widianingrum, R., 2012, Efektifitas Penyuluhan Tentang Hipertensi Masayarakat Rentang Usia 45-60 tahun Dibandingkan dengan Masyarakat Rentang Usia 61-75 tahun, Skripsi, Fakultas Kedokteran Universitas Muhammadiyah Semarang.

Wongsawat, S., 2015, Integrating Poster and Actual-Sized Fruit Models in Health Education on Fruit Diets for Elderly Patient, International Journal of Arts \& Sciences.

Yanti, H. I., 2008, Hubungan Antara Pengetahuan Keluarga Tentang Komplikasi Hipertensi dengan Praktek Pencegahan Komplikasi Hipertensi di Wilayah Kerja Puskesmas Gamping II Sleman Yogyakarta, Skripsi, Universitas Muhammadiyah Yogyakarta. 